\title{
Lipopolysaccharide Binding Protein and Cardiovascular Changes in Obese Children
}

\section{Eatemad Nabil Mansour*, Mervat Elshahat Elwakeel, Ola Hassan Abd Elaziz, Walaa Mohammed Shipl}

Alzahraa University Hospital, Faculty of Medicine for Girls, Al-Azhar University, Cairo, Egypt

Email: *eatemad_nabil@yahoo.com

How to cite this paper: Mansour, E.N., Elwakeel, M.E., Elaziz, O.H.A. and Shipl, W.M. (2021) Lipopolysaccharide Binding Protein and Cardiovascular Changes in Obese Children. Open Journal of Pediatrics, 11, 225-237. https://doi.org/10.4236/ojped.2021.112022

Received: April 6, 2021

Accepted: June 5, 2021

Published: June 8, 2021

Copyright $\odot 2021$ by author(s) and Scientific Research Publishing Inc. This work is licensed under the Creative Commons Attribution International License (CC BY 4.0).

http://creativecommons.org/licenses/by/4.0/

(c) (i) Open Access

\begin{abstract}
Objective: Despite the growing evidence that lipopolysaccharide binding protein (LBP) plays a major role in cardiovascular disease (CVD) pathophysiology and obesity, data regarding this association in children are rare. Therefore, our objectives were to assess whether there was a difference between overweight/obese and normal-weight children in plasma LBP levels and to assess the cardiovascular changes in both groups. Methods: In an observational, case-control study, a total of 30 children as obese and overweight children. Obese children with body mass index (BMI) above $95^{\text {th }}$ percentile, and overweight children with BMI between $85^{\text {th }}$ and $95^{\text {th }}$ percentile were recruited if they aged between 8-16 years old. A similar number of matched controls were included. Serum LBP was measured by enzyme-linked immunosorbent assay (ELISA) technique. Results: With regard to serum LBP, the mean LBP was significantly higher in obese children than in the control group ( $52.74 \pm 17.25$ versus $12.34 \pm 2.67 \mu \mathrm{g} / \mathrm{mL}$, respectively; $\mathrm{p}<0.001)$. The ROC curve showed that the serum LBP, at a cutoff value of $>19 \mu \mathrm{g} / \mathrm{mL}$, was a significant discriminator of obesity with a sensitivity of $96.67 \%$ and specificity of $100 \%$. The regression analysis showed that BMI was an independent predictor of serum LBP ( $B$ coefficient $=0.684 ; p=0.024$ ). The serum LBP correlated significantly with age $(\mathrm{r}=0.58 ; \mathrm{p}=0.001)$, BMI $(\mathrm{r}=0.834 ; \mathrm{p}=0.001)$, and LV longitudinal strain $(r=0.362 ; p=0.05)$. Conclusion: In conclusion, our findings showed that obesity was associated with a worse lipid profile and cardiovascular function. LBP is a promising predictor of obesity in children.
\end{abstract}

\section{Keywords}

Obesity, Echocardiographic Changes, Lipopolysaccharide Binding Protein 


\section{Introduction}

Childhood obesity is growing globally, with a significant public health burden [1]. Recently, many studies indicated that overweight and obesity of childhood frequently persist in adulthood and are linked to increased morbidity and mortality, such as the increased risk of cardiovascular diseases (CVD), which lead to premature death [2] [3] [4]. It has become apparent in recent years that there is a strong association between the increasing levels of various inflammatory biomarkers and childhood obesity [5] [6]. Nevertheless, the underlying mechanisms that induce the elevated inflammatory burden still unclear. The gut microbiome is one of the most important sources of pro-inflammatory factors [7] [8]. The increased microbial translocation, especially lipopolysaccharide (LPS), was reported to be linked with childhood obesity [9].

Lipopolysaccharide (LPS) is a well-defined pathogen-associated molecular model, which presents in the outer leaflet of most gram-negative bacteria in the outer membrane [10]. LPS may lead to an inflammatory response by activation of monocytes and endothelial cells when absorbed or translocated into intestinal capillaries [11]. The detection of LPS involves soluble proteins, such as Lipopolysaccharide binding protein (LBP) and soluble CD14 (sCD14), which generate and secrete a broad range of response mediators [12] [13]. Throughout the past two decades, several measures have been seen in the LPS-based inflammatory, antibacterial response.

Lipopolysaccharide binding protein (LBP) is produced mainly through hepatocytes and expressed and released through intestinal and visceral adipocytes [14] [15]. Plasma LBP levels are dramatically increased in response to inflammatory challenges [16]. LBP is well-known for binding to LPS substructures, for example, lipid IVa [17]. Plasma LBP significantly accelerates the connection between the LPS monomers released from aggregates and CD14 [18]. LBP counteracts the LPS effect by transferring LPS to lipoproteins.

Several articles were demonstrated an association between coronary artery disease prevalence and the serum of LBP [19] [20] [21] [22]. Furthermore, serum LBP levels were shown to be correlated with metabolic syndrome and type 2 diabetes [10] [18] [23].

Despite the growing evidence that LBP plays a major role in CVD pathophysiology and obesity, data regarding this association in children are rare. Therefore, our objectives were to assess whether there was a difference between overweight/obese and normal-weight children in plasma LBP levels and to assess the cardiovascular changes in both groups.

\section{Material and Methods}

\subsection{Design and Population}

In an observational, case-control, study, a total of 30 obese children were recruited from Pediatric and Endocrinology Outpatient Clinics of Al Zahraa University Hospital. Children were included if they aged between $8-16$ years old 
and had a body mass index (BMI) above $95^{\text {th }}$ percentile. In addition, 30 children, with a BMI of less than $95^{\text {th }}$ percentile, were included as a control group. We excluded children with history of cardiovascular (CV) diseases or other chronic disorders (such as pulmonary or renal diseases), non-endocrinal or syndromic obesity, renal or hepatic failure, familial dyslipidemia, immunological diseases, and/or patients with acute or chronic infection. The study was conducted from September 2019 to February 2020 after the approval of local ethics committee (IRB No. 202005256) and written informed consents, signed by the parents, were a prerequisite for inclusion of eligible children.

\subsection{Data Collection and Laboratory Investigations}

After detailed history taking, eligible patients underwent physical examination to determine height, weight, BMI, and blood pressure. The laboratory investigation included complete blood count ( $\mathrm{CBC}$ ), hepatic function, lipid profile, blood glucose profile, thyroid functions, and serum LBP, while imaging investigations included carotid Duplex and echocardiography.

For laboratory investigations, $5 \mathrm{~mL}$ of venous blood were withdrawn from each child, and then centrifuged. The serum was separated and divided into two portions. The first portion used for blood cholesterol, high density lipoprotein (HDL), low density lipoprotein (LDL), and triglycerides (Cobas Integra 400 plus, Roche diagnostics, Germany). The second portion was stored at-20 until be used for LBP assessment, which was measured by enzyme-linked immunosorbent assay (ELISA) technique using the kitof Catalog (Number MBS704355 and Lot No. H1560E116. My Biosource comp; USA). The reference range was 0.625 - 40 $\mu \mathrm{g} / \mathrm{ml}$ according to manufacturer instructions with the limit of detection 3.125 $200 \mathrm{ng} / \mathrm{ml}$ and a sensitivity of $1.875 \mathrm{ng} / \mathrm{ml}$.

\subsection{Echocardiography}

Children were instructed to lie in the left lateral recumbent position to perform the 2D, transthoracic echocardiographic examination using Vivid E9 (GE Ultrasound, Horten, Norway) ultrasound machine with a multifrequency probe (2.5 $\mathrm{MHz}$ ). Both apical and parasternal axial views were used for comprehensive assessment, which included Doppler and color flow mapping parameters. The LV mass was calculated using modified Penn formula. The pulsed Doppler parameters included early (e) and late (a) diastolic velocity across the mitral valve, E/A ratio, and deceleration time. The tissue Doppler imaging (TDI) parameters for LV (averaged across four mitral annuli) and RV (at RV free wall) assessment included Sm, Em, and Am. Additionally the Speckle-tracking echocardiography (STE) analysis was used to obtain the LV and RV global longitudinal strain via Echo PAC version 210. In addition, the left atrium volume index (LAVI) was calculated through obtained the maximum and minimum volumes the end of $\mathrm{T}$ wave and at the onset of QRS wave, followed by the calculation of LAVI by incorporating the body surface area [24] [25]. Other parameters for RV systolic 
function included tricuspid annular plane systolic excursion (TAPSE) and fractional area change (FAC) were assessed [26]. All measurements were obtained using two-to-three consecutive cardiac cycles.

\subsection{Carotid Duplex}

In all recruited participants, the carotid Duplex was performed using General Electric (GE) system 7 machines, with $10 \mathrm{MHz}$ transducer. Patient was placed in supine position with chin extended and the head was rotated away from side to be examined, it is helpful to put a pillow below patient's shoulder for hyperextension of the neck as recommended by the 2007 Mannheim Consensus. Image was focused on the posterior wall of each common carotid artery, in a segment 1 $\mathrm{cm}$ proximal to the carotid bifurcation on each side. We solely assessed the intima (echogenic line) and the media (hypoechoic line) for assessment of intima-media thickness (IMT). IMT for common carotid artery of both sides were assessed [27].

\subsection{Statistical Analysis}

The SPSS version 20.0 (SPSS Inc., Chicago, Illinois, USA) was used for data analysis. The continuous and dichotomous data were summarized in the form of the quantitative mean \pm standard deviation (SD) and frequency (percentages), respectively. The association between continuous and dichotomous data was examined by independent-samples t-test or Mann-Whitney test. Chi squared test was applied to test the hypotheses in categorical variables. Null hypothesis was rejected when $\mathrm{p}$ value at level less than 0.05 .

\section{Results}

In this case-control study, 30 obese children (mean age $10.48 \pm 1.99$ years; females $=56.7 \%)$ and 30 matched controls (mean age $11.42 \pm 2.03$ years; females $=$ $50 \%)$. As expected, the patients' weight, BMI, and waist circumference were significantly higher than the control group $(\mathrm{p}<0.001)$. Likewise, the mean arterial blood pressure, serum LDL, HLD, and cholesterol were significantly higher in obese children than the control group ( $<0.001$; Table 1$)$.

In terms of echocardiographic findings, the mean aortic root and LAVI were significantly higher in the obese children than the control group $(\mathrm{p}<0.001)$. Obese children had significantly higher interventricular septum $(p<0.001)$, posterior wall diameter $(\mathrm{p}<0.001), \mathrm{LV}$ end diastolic diameter $(\mathrm{p}<0.001)$, stroke volume $(\mathrm{p}<0.001)$, LV mass index $(\mathrm{p}<0.001)$, relative wall thickness $(\mathrm{p}=$ $0.035)$, mitral $\mathrm{E} / \mathrm{A}$ ratio $(\mathrm{p}=0.011)$, mitral annular systolic velocity $(\mathrm{Sm})(\mathrm{p}<$ $0.001)$, mitral annular early diastolic velocity $\mathrm{Em}(\mathrm{p}=0.005)$, and lower ejection fraction $(\mathrm{p}<0.001)$ and LVGL strain $(\mathrm{p}=0.02)$ than the control group. On the other hand, the obese children had apparent RV dysfunction as evident by the lower TAPSE, RV global strain, and FAC ( $\mathrm{p}<0.001$; Table 2).

In terms of carotid Dupplex findings, we demonstrated higher CIMT in patients 
than control group $(0.08 \pm 0.01$ versus $0.04 \pm 0.01 \mathrm{~mm} ; \mathrm{P}<0.001$; Figure 1$)$.

With regard to serum LBP, the mean LBP was significantly higher in obese children than the control group $(52.74 \pm 17.25$ versus $12.34 \pm 2.67 \mu \mathrm{g} / \mathrm{mL}$, respectively; $\mathrm{p}<0.001$; Figure 2). The ROC curve showed that the serum LBP, at a cutoff value of $>19 \mu \mathrm{g} / \mathrm{mL}$, was significant discriminator of obesity with a sensitivity of $96.67 \%$ and specificity of $100 \%$ (Figure 3 ). The regression analysis showed that BMI was independent predictor of serum LBP (B coefficient = $0.684 ; \mathrm{p}=0.024)$.

The serum LBP correlated significantly with age $(\mathrm{r}=0.58 ; \mathrm{p}=0.001)$, BMI $(\mathrm{r}$ $=0.834 ; \mathrm{p}=0.001)$, and LV longitudinal strain $(\mathrm{r}=0.362 ; \mathrm{p}=0.05 ;$ Table 3$)$.

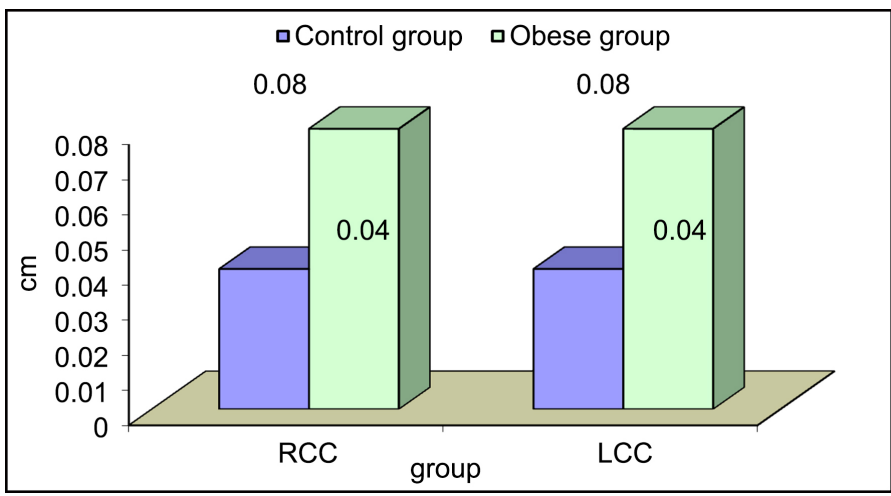

Figure 1. Comparison between obese and control group as regard carotid intma-media thickness.

Table 1. Baseline demographic, clinical data and lipid profile of study groups.

\begin{tabular}{cccccc}
\hline & & $\begin{array}{c}\text { Control group } \\
\text { No. }=30\end{array}$ & $\begin{array}{c}\text { Obese group } \\
\text { No. }=30\end{array}$ & p-value & sig \\
\hline Sex & Female & $15(50 \%)$ & $17(56.7 \%)$ & 0.605 & NS \\
Age (yrs) & Male & $15(50 \%)$ & $13(43.3 \%)$ & & \\
Weight (KG) & Mean \pm SD & $45.63 \pm 7.31$ & $69.07 \pm 21.76$ & 0.000 & HS \\
Height (cm) & Mean \pm SD & $146.93 \pm 9.36$ & $140.47 \pm 10.88$ & 0.017 & S \\
BSA & Mean \pm SD & $1.36 \pm 0.15$ & $1.67 \pm 0.37$ & 0.000 & HS \\
BMI & Mean \pm SD & $21.09 \pm 1.67$ & $34.14 \pm 5.84$ & 0.000 & HS \\
Waist (cm) & Mean \pm SD & $73.23 \pm 5.08$ & $96.87 \pm 12.89$ & 0.000 & HS \\
Waist.height & Mean \pm SD & $0.50 \pm 0.03$ & $0.69 \pm 0.05$ & 0.000 & HS \\
Systolic BP mmHg & Mean \pm SD & $109.5 \pm 5.47$ & $125.67 \pm 4.5$ & 0.000 & HS \\
Diastolic BP mmHg & Mean \pm SD & $67.33 \pm 5.37$ & $82.33 \pm 4.5$ & 0.000 & HS \\
Cholest. (mg/dl) & Mean \pm SD & $111.43 \pm 7.53$ & $128.73 \pm 19.38$ & 0.000 & HS \\
LDL (mg/dl) & Mean \pm SD & $91.43 \pm 5.92$ & $98.3 \pm 5.29$ & 0.000 & HS \\
HDL (mg/dl) & Mean \pm SD & $26.67 \pm 3.74$ & $30.33 \pm 2.23$ & 0.000 & HS \\
TG (mg/dl) & Mean \pm SD & $122.4 \pm 9.65$ & $133.17 \pm 8.6$ & 0.000 & HS \\
\hline
\end{tabular}

Abbreviation: $\mathrm{BSA}=$ body surface area; $\mathrm{BMI}=$ body mass index; cholest $=$ cholesterol; $\mathrm{LDL}=$ low density lipoprotein; HDL = high density lipoprotein; TG = triglyceride. 
Table 2. Echocardiographic parameters in the study population.

\begin{tabular}{|c|c|c|c|c|}
\hline & $\begin{array}{c}\text { Control group } \\
\text { No. }=30\end{array}$ & $\begin{array}{c}\text { Obese group } \\
\text { No. }=30\end{array}$ & $\mathrm{p}$-value & sig \\
\hline Ao $(\mathrm{cm})$ & $2.35 \pm 0.2$ & $2.64 \pm 0.27$ & 0.000 & HS \\
\hline $\mathrm{LAD}(\mathrm{cm})$ & $2.61 \pm 0.23$ & $3.08 \pm 0.32$ & 0.000 & HS \\
\hline Ratio & $1.18 \pm 0.19$ & $1.18 \pm 0.12$ & 0.954 & NS \\
\hline IVSd $(\mathrm{cm})$ & $0.68 \pm 0.07$ & $0.81 \pm 0.13$ & 0.000 & HS \\
\hline LVPWd (cm) & $0.68 \pm 0.07$ & $0.8 \pm 0.15$ & 0.000 & HS \\
\hline LVDD (cm) & $4.34 \pm 0.43$ & $4.58 \pm 0.58$ & 0.077 & NS \\
\hline LVDS (cm) & $2.64 \pm 0.36$ & $2.79 \pm 0.44$ & 0.152 & NS \\
\hline LVVD (ml) & $74.17 \pm 14.21$ & $97.5 \pm 30.01$ & 0.000 & NS \\
\hline LVVS (ml) & $28.13 \pm 8.52$ & $32.07 \pm 12.98$ & 0.170 & NS \\
\hline SV & $52.17 \pm 11.93$ & $69.4 \pm 15.37$ & 0.000 & HS \\
\hline FS (\%) & $40 \pm 4.43$ & $38.73 \pm 3.86$ & 0.242 & NS \\
\hline $\mathrm{EF}(\%)$ & $73.67 \pm 4.47$ & $70.03 \pm 4.36$ & 0.002 & HS \\
\hline LVmass & $85.67 \pm 15.18$ & $121.3 \pm 42.58$ & 0.000 & HS \\
\hline $\operatorname{LVMI}\left(\mathrm{g} / \mathrm{m}^{2}\right)$ & $60.47 \pm 12.3$ & $77.27 \pm 28.42$ & 0.004 & HS \\
\hline RWT (cm) & $0.32 \pm 0.05$ & $0.35 \pm 0.07$ & 0.035 & S \\
\hline ME velocity $(\mathrm{m} / \mathrm{s})$ & $0.82 \pm 0.15$ & $1.01 \pm 0.16$ & 0.000 & HS \\
\hline MAvelocity (m/s) & $0.66 \pm 0.11$ & $0.69 \pm 0.19$ & 0.546 & NS \\
\hline ME.A & $1.28 \pm 0.37$ & $1.55 \pm 0.44$ & 0.011 & S \\
\hline M.Dec.T & $174.57 \pm 21.23$ & $164.63 \pm 21.38$ & 0.076 & NS \\
\hline $\operatorname{LVSm}(\mathrm{cm} / \mathrm{s})$ & $8.58 \pm 1.15$ & $7.6 \pm 1.04$ & 0.001 & HS \\
\hline $\operatorname{LVEm}(\mathrm{cm} / \mathrm{s})$ & $12.27 \pm 2.04$ & $10.6 \pm 2.39$ & 0.009 & HS \\
\hline $\operatorname{LVAm}(\mathrm{cm} / \mathrm{s})$ & $9.14 \pm 2.21$ & $6.4 \pm 1.2$ & 0.000 & HS \\
\hline LVE.Em & $6.85 \pm 1.98$ & $9.83 \pm 1.87$ & 0.000 & HS \\
\hline LVGLS TDI (\%) & $21.84 \pm 1.57$ & $20.83 \pm 1.7$ & 0.020 & $S$ \\
\hline LVGLS 2STE (\%) & $20.39 \pm 1.38$ & $19.97 \pm 1.72$ & 0.293 & NS \\
\hline TVE velocity $(\mathrm{m} / \mathrm{s})$ & $0.64 \pm 0.09$ & $0.73 \pm 0.29$ & 0.112 & NS \\
\hline TVAvelocity $(\mathrm{m} / \mathrm{s})$ & $0.53 \pm 0.1$ & $7.76 \pm 1.54$ & 0.142 & NS \\
\hline TVE.A & $1.25 \pm 0.17$ & $1.25 \pm 0.28$ & 0.964 & NS \\
\hline TV Dec.T (msec) & $178.87 \pm 19.61$ & $170.4 \pm 33.07$ & 0.233 & NS \\
\hline TV Sm $(\mathrm{cm} / \mathrm{s})$ & $12.97 \pm 1.63$ & $8.48 \pm 0.87$ & 0.000 & HS \\
\hline TV Em $(\mathrm{cm} / \mathrm{s})$ & $13.07 \pm 2.08$ & $7.46 \pm 2.2$ & 0.000 & HS \\
\hline $\mathrm{TV} \operatorname{Am}(\mathrm{cm} / \mathrm{s})$ & $10.38 \pm 2.06$ & $7.76 \pm 1.54$ & 0.000 & HS \\
\hline TV E.Em & $4.92 \pm 0.66$ & $9.5 \pm 1.33$ & 0.000 & HS \\
\hline TAPSE (mm) & $20.97 \pm 2.39$ & $15.71 \pm 1.48$ & 0.000 & HS \\
\hline RVGLS (\%) & $24.9 \pm 1.88$ & $15.3 \pm 2.17$ & 0.000 & HS \\
\hline FAC (\%) & $64.27 \pm 4.58$ & $55.1 \pm 8.68$ & 0.000 & HS \\
\hline LA volume & $26.57 \pm 3.39$ & $41.73 \pm 8.5$ & 0.000 & HS \\
\hline LAVI & $19.9 \pm 4.06$ & $25.73 \pm 6.58$ & 0.000 & HS \\
\hline
\end{tabular}

Abbreviation: Ao, aortic; LAD, left atrial dimensions; IVSd, interventricular septal thickness in diastole; LVIDd, left ventricular internal dimension in diastole; LVIDs, left ventricular internal dimension in systole; LVPWd, left ventricular posterior wall thickness in diastole; LVDD, left ventricular dimension in diastole; LVDS, left ventricular dimension in systole; LVVD, left ventricular volume in diastole; LVVS, left ventricular volume in systole; SV, stroke volume; FS, fractional of shorting; EF, ejection fraction; LVMI, left ventricle mass index; RWT, Relative wall thickness; MV, mitral valve; E vel, early diastolic velocity; A vel, late diastolic or atrial velocity; TDI, tissue Doppler imaging; LVSm, myocardial systolic excursion velocity; LVEm, myocardial early diastolic excursion velocity; LV Am, myocardial late diastolic velocity; E/Ea, early diastolic velocity measured by pulsed-Doppler/myocardial early diastolic excursion velocity measured by tissue Doppler echocardiography; LVGLS TDI, left ventricular global longitudinal stain by tissue Doppler; LVGLS 2STE, left ventricular global longitudinal strain by 2D speckle tracking; TV, tricuspid valve; FAC, fractional area change; TAPSE, tricuspid annular plane systolic excursion; LAVI, left atrial volume index. 
Table 3. Correlation between LBP level and different variables.

\begin{tabular}{ccc}
\hline & \multicolumn{2}{c}{ LBP $(\mathrm{mic} / \mathrm{ml})$} \\
\cline { 2 - 3 } & $\mathrm{r}$ & p-value \\
\hline Age $(\mathrm{yrs})$ & $0.581^{* *}$ & 0.001 \\
Weight $(\mathrm{kg})$ & $0.715^{* *}$ & 0.000 \\
Height $(\mathrm{cm})$ & $0.449^{*}$ & 0.013 \\
BSA & $0.652^{* *}$ & 0.000 \\
BMI & $0.834^{* *}$ & 0.000 \\
WC & $0.459^{*}$ & 0.011 \\
LV strain TDI & 0.362 & 0.050 \\
\hline
\end{tabular}

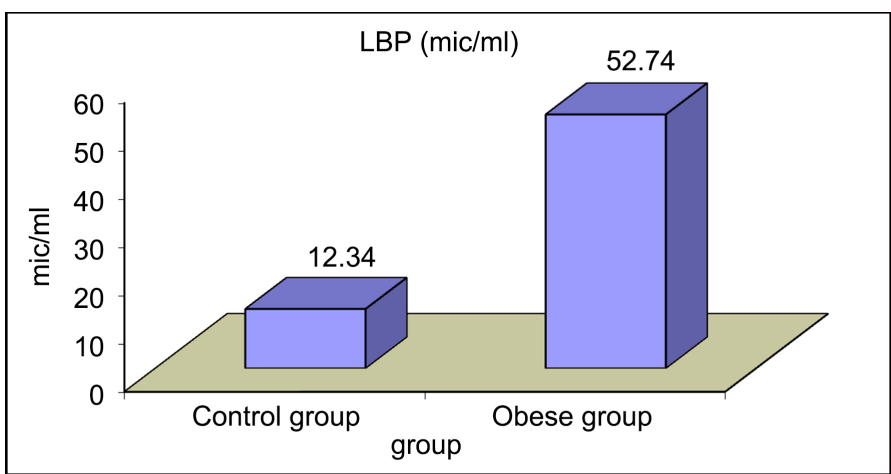

Figure 2. Comparison between obese and control group as regard LBP level.

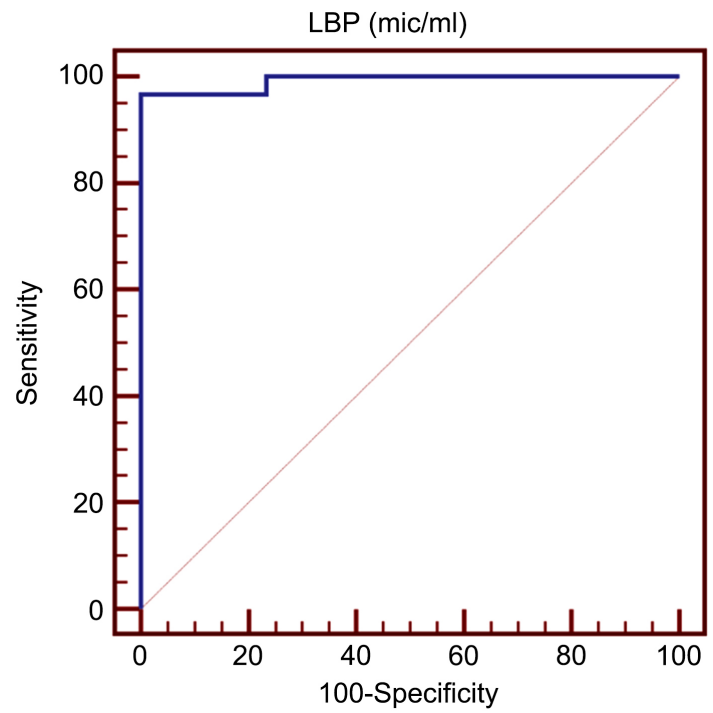

Figure 3. Roc analysis of LBP and best cut off value to discriminate obesity.

\section{Discussion}

To the best of our knowledge, the correlation between the serum LBP levels and the presence of atherosclerosis and CVD was reported in several epidemiological 
studies [19] [20] [28]. Moreover, a significant positive association between the serum level of LBP and atherosclerosis was reported by two cross-sectional studies as assessed by aortic pulse wave velocity and carotid intima-media thickness [13] [29]. Furthermore, Lepper's study showed that patients with higher serum LBP levels were significantly associated with increased all-cause and cardiovascular mortality risks [20].

The Hisayama study has shown that higher LBP serum levels, even after adjustment to conventional risk factors, are significantly correlated with the development of CVD, insulin resistance index, and HOMA-IR. For the CVD subtypes, participants with greater serum levels of LBP were at significantly more risk of stroke, especially ischemic stroke, while hemorrhagic stroke was not statistically significant. The CHD incidence showed a tendency to grow, but this correlation was not statistically significant with high serum LBP levels [30].

Regarding the interventricular septum (IVS), our findings indicated that obese children had a thicker IVS than control $(<0.001)$. Similarly, Schusterova and his colleagues demonstrated a significant association between overweight/obesity and IVS compared to normal individuals $(\mathrm{p}<0.01)$ [31]. In contrast, Balaji et al. showed that the IVS was comparable in both obese children and normal group $(p=0.11)$ [32]. Regarding the association between IVS and the serum level of BLP, we could not find any significant association $(r=0.20, p=0.271)$.

In addition, we observed that the Ao, LAD, LVVD, and SV were significantly increased in obese children $(p<0.001)$. These findings were in agreement with the previous literature [31] [32] [33]. However, all of these parameters were not significantly associated with LBP level, which requires further studies with larger samples to explore this association. Similarly, LV mass, LV mass index, and I were significantly increased in the obese groups without any significant association with LBP serum levels. Mangner et al. compared obese children and non-obese children regarding the echocardiographic parameters and showed a significant increase in the following parameters in obese children: IVSd, PWd, LVEDD, LVM, LVMI, SV, and LA diameter. In terms of LVEF, both groups were comparable $(\mathrm{p}=0.4)$. Obesity leads to greater overall blood volume, cardiac output, heart and peripheral resistance. Increases in pressure and volume lead to dilation of cardiac chambers because of the increased filling [34]. It is proved that adverse cardiac events and worse prognosis are associated with LV dilation and LV hypertrophy, as well as LA enlargement. In addition, increased LA size is also a feature of left ventricle impaired diastolic function [35].

Concerning the LV E/Em and LAVI we found a significant increase in obese children compared to the normal group ( $\mathrm{p}<0.001)$, indicating an impairment in the LV diastolic function. The impact of obesity on the LV diastolic function can be attributed to the workload exerted by obesity on cardiac function, which, in return, leads to dilatation and hypertrophy [36]. However, in terms of LVGLS, we could not find any significant difference between both groups $(\mathrm{p}=0.293)$. In agreement, Yang et al., showed that LVGLS could be used as an independent 
predictor in adults more than in children [37]. On the other hand, we found a significant decrease in TAPSE, RVGLS and FAC among patients' group ( $\mathrm{p}<$ 0.001), indicating a global impairment in RV systolic function. Sleep disorders are prevalent among obese individuals; alongside excessive cardiac output, these sleep disorders can significantly increase the pulmonary artery pressure leading to subsequent dysfunction in RV. In previous study by Sokmen et al. [36], subclinical RV dysfunction was noted among young obese patients as noted in this study. However, according to Zeller and his colleagues, the found that parameters of RV function and dimension of right heart chambers were comparable to non-obese subjects even extremely obese subjects (with BMI $>40 \mathrm{~kg} / \mathrm{m}^{2}$ ) had no greater impairment of RV function according to TAPSE [38]. Thus, a future study investigating the RV function in obese patients is warranted.

CIMT is a well-established marker for early atherosclerosis, as well as other vascular abnormalities, in children and adults. Previous reported indicated higher thickness of CIM in pediatric population with hypertension [39] and other cardiovascular diseases [40]. Moreover, the current body of evidence suggests that CIMT is significantly positively correlated with the degree of obesity and other metabolic abnormalities in children [41]. In the present study, we demonstrated higher CIMT in patients than control group $(0.08 \pm 0.01$ versus $0.04 \pm 0.01 \mathrm{~mm} ; \mathrm{P}<0.001)$. These findings are line with previous reports showing higher CIMT values in obese children than normal weight controls [42] [43]. However, in the present study, the serum LBP did not correlate significantly with CIMT. On the contrary, Serrano et al. [13], demonstrated positive correlation between serum LBP and CIMT. Thus, further studies are warranted to characterize the association between serum LBP and markers of atherosclerosis, like CIMT.

On the other hand, LBP serum level was significantly associated with age $(\mathrm{r}=$ $0.58, \mathrm{p}=0.001)$, weight $(\mathrm{r}=0.71, \mathrm{p}<0.001)$, height $(\mathrm{r}=0.449, \mathrm{p}=0.013)$, BSA $(\mathrm{r}$ $=0.652, \mathrm{p}<0.001)$, BMI $(\mathrm{r}=0.834, \mathrm{p}<0.001)$, and WC $(\mathrm{r}=0.459, \mathrm{p}=0.01)$. These findings confirm the association between LBP level and obesity. Furthermore, the LV strain by tissue-Doppler imaging was found to be significantly associated with LBP serum level $(r=0.362, p=0.050)$. In multivariate analysis, only BMI was observed to be significantly associated with LBP $(\mathrm{B}=2.021, \mathrm{p}=$ $0.024)$.

\section{Limitations}

One of the major limitations in our study is the small number of included children. Another factor is that we considered both overweight children and obese children as one group. Also it is better to measure the bacterial endotoxin lipopolysaccharide itself rather than measuring its binding protein. However it is more costly.

In conclusion, our findings showed that obesity was associated with worse lipid profile and cardiovascular function. LBP is a promising predictor of obesity 
in children. Further studies are required for more exploration about the association between the LBP as a biomarker for cardiovascular disease in obese children.

\section{Conflicts of Interest}

The authors declare no conflicts of interest regarding the publication of this paper.

\section{References}

[1] Huffman, M.D., Capewell, S., Ning, H., Shay C.M., Ford, E.S. and Lloyd-Jones, D.M. (2012) Cardiovascular Health Behavior and Health Factor Changes (1988-2008) and Projections to 2020: Results from the National Health and Nutrition Examination Surveys. Circulation, 125, 2595-2602. https://doi.org/10.1161/CIRCULATIONAHA.111.070722

[2] Zhang, N. and Ma, G. (2018) Interpretation of WHO Guideline: Assessing and Managing Children at Primary Health-Care Facilities to Prevent Overweight and Obesity in the Context of the Double Burden of Malnutrition. Global Health Jour nal, 2, 1-13. https://doi.org/10.1016/S2414-6447(19)30136-8

[3] Reilly, J.J. and Kelly, J. (2011) Long-Term Impact of Overweight and Obesity in Childhood and Adolescence on Morbidity and Premature Mortality in Adulthood: Systematic Review. International Journal of Obesity, 35, 891-898. https://doi.org/10.1038/ijo.2010.222

[4] Alexander, S. (2012) Health Implications of Overweight and Obesity in Children and Adolescents. In: Baur, L., Twigg, S.M. and Magnusson, R.S., Eds., A Modern Epidemic. Expert Perspectives on Obesity and Diabetes, Sydney University Press, Sydney, 160-170.

https://ses.library.usyd.edu.au/bitstream/handle/2123/12564/9781920899851_Chapt er_10.pdf? sequence $=3$

[5] de Heredia, F.P., Gómez-Martínez, S. and Marcos, A. (2012) Obesity, Inflammation and the immune System. Proceedings of the Nutrition Society, 71, 332-338. https://doi.org/10.1017/S0029665112000092

[6] Hotamisligil, G.S. (2006) Inflammation and Metabolic Disorders. Nature, 444, 860-867. https://doi.org/10.1038/nature05485

[7] Tremaroli, V. and Bäckhed, F. (2012) Functional Interactions between the Gut Microbiota and Host Metabolism. Nature, 489, 242-249. https://doi.org/10.1038/nature11552

[8] Sommer, F. and Bäckhed, F. (2013) The Gut Microbiota-Masters of Host Development and Physiology. Nature Reviews Microbiology, 11, 227-238. https://doi.org/10.1038/nrmicro2974

[9] Shen, J., Obin, M.S. and Zhao, L. (2013) The Gut Microbiota, Obesity and Insulin Resistance. Molecular Aspects of Medicine, 34, 39-58. https://doi.org/10.1016/j.mam.2012.11.001

[10] Gonzalez-Quintela, A., Alonso, M., Campos, J., Vizcaino, L., Loidi, L. and Gude, F. (2013) Determinants of Serum Concentrations of Lipopolysaccharide-Binding Protein (LBP) in the Adult Population: The Role of Obesity. PLoS ONE, 8, e54600. https://doi.org/10.1371/journal.pone.0054600

[11] Luoto, R., Kalliomäki, M., Laitinen, K., Delzenne, N.M., Cani, P.D., Salminen, S., et 
al. (2011) Initial Dietary and Microbiological Environments Deviate in Normal-Weight Compared to Overweight children at 10 Years of Age. Journal of Pediatric Gastroenterology and Nutrition, 52, 90-95. https://doi.org/10.1097/MPG.0b013e3181f3457f

[12] Moreno-Navarrete, J.M., Ortega, F., Serino, M., Luche, E., Waget, A., Pardo, G., et al. (2012) Circulating Lipopolysaccharide-Binding Protein (LBP) as a Marker of Obesity-Related Insulin Resistance. International Journal of Obesity, 36, 1442-1449. https://doi.org/10.1038/ijo.2011.256

[13] Serrano, M., Moreno-Navarrete, J.M., Puig, J., Moreno, M., Guerra, E., Ortega, F., et al. (2013) Serum Lipopolysaccharide-Binding Protein as a Marker of Atherosclerosis. Atherosclerosis, 230, 223-227.

https://doi.org/10.1016/j.atherosclerosis.2013.07.004

[14] Greenberg, A.S. and Obin, M.S. (2006) Obesity and the Role of Adipose Tissue in Inflammation and Metabolism. American Journal of Clinical Nutrition, 83, 461S-465S. https://doi.org/10.1093/ajcn/83.2.461S

[15] Ouchi, N., Parker, J.L., Lugus, J.J. and Walsh, K. (2011) Adipokines in Inflammation and Metabolic Disease. Nature Reviews Immunology, 11, 85-97.

https://doi.org/10.1038/nri2921

[16] Ghanim, H., Abuaysheh, S., Sia, C.L., Korzeniewski, K., Chaudhuri, A., Fernandez-Real, J.M., et al. (2009) Increase in Plasma Endotoxin Concentrations and the Expression of Toll-Like Receptors and Suppressor of Cytokine Signaling-3 in Mononuclear Cells after a High-Fat, High-Carbohydrate Meal: Implications for Insulin Resistance. Diabetes Care, 32, 2281-2287. https://doi.org/10.2337/dc09-0979

[17] Liu, X., Lu, L., Yao, P., Ma, Y., Wang, F., Jin, Q., et al. (2014) Lipopolysaccharide Binding Protein, Obesity Status and Incidence of Metabolic Syndrome: A Prospective Study among Middle-Aged and Older Chinese. Diabetologia, 57, 1834-1841. https://doi.org/10.1007/s00125-014-3288-7

[18] Kheirandish-Gozal, L., Peris, E., Wang, Y., Kakazu, M.T., Khalyfa, A., Carreras, A., et al. (2014) Lipopolysaccharide-Binding Protein Plasma Levels in Children: Effects of Obstructive Sleep Apnea and Obesity. Journal of Clinical Endocrinology \& Metabolism, 99, 656-663. https://doi.org/10.1210/jc.2013-3327

[19] Lepper, P.M., Schumann, C., Triantafilou, K., Rasche, F.M., Schuster, T., Frank, H., et al. (2007) Association of Lipopolysaccharide-Binding Protein and Coronary Artery Disease in Men. Journal of the American College of Cardiology, 50, 25-31. https://doi.org/10.1016/j.jacc.2007.02.070

[20] Lepper, P.M., Kleber, M.E., Grammer, T.B., Hoffmann, K., Dietz, S., Winkelmann, B.R., et al. (2011) Lipopolysaccharide-Binding Protein (LBP) Is Associated with Total and Cardiovascular Mortality in Individuals with or without Stable Coronary Artery Disease-Results from the Ludwigshafen Risk and Cardiovascular Health Study (LURIC). Atherosclerosis, 219, 291-297. https://doi.org/10.1016/j.atherosclerosis.2011.06.001

[21] Silbernagel, G., Schöttker, B., Appelbaum, S., Scharnagl, H., Kleber, M.E., Grammer, T.B., et al. (2013) High-Density Lipoprotein Cholesterol, Coronary Artery Disease, and Cardiovascular Mortality. European Heart Journal, 34, 3563-3571. https://doi.org/10.1093/eurheartj/eht343

[22] Scharnagl, H., Kleber, M.E., Genser, B., Kickmaier, S., Renner, W., Weihrauch, G., et al. (2014) Association of Myeloperoxidase with Total and Cardiovascular Mortality in Individuals Undergoing Coronary Angiography-The LURIC Study. International Journal of Cardiology, 174, 96-105.

https://doi.org/10.1016/j.ijcard.2014.03.168 
[23] Guerra Ruiz, A., Casafont, F., Crespo, J., Cayón, A., Mayorga, M., Estebanez, A., et al. (2007) Lipopolysaccharide-Binding Protein Plasma LEVELS and Liver TNF-Alpha Gene Expression in Obese Patients: Evidence for the Potential Role of Endotoxin in the Pathogenesis of Non-Alcoholic Steatohepatitis. Obesity Surgery, 17, Article No. 1374. https://doi.org/10.1007/s11695-007-9243-7

[24] Lopez, L., Colan, S.D., Frommelt, P.C., Ensing, G.J., Kendall, K., Younoszai, A.K., et al. (2010) Recommendations for Quantification Methods During the Performance of a Pediatric Echocardiogram: A Report From the Pediatric Measurements Writing Group of the American Society of Echocardiography Pediatric and Congenital Heart Disease Council. Journal of the American Society of Echocardiography, 23, 465-495. https://doi.org/10.1016/j.echo.2010.03.019

[25] Lang, R.M., Badano, L.P., Mor-Avi, V., Afilalo, J., Armstrong, A., Ernande, L., et al. (2015) Recommendations for Cardiac Chamber Quantification by Echocardiography in Adults: An Update from the American Society of Echocardiography and the European Association of Cardiovascular Imaging. European Heart Journal-Cardiovascular Imaging, 16, 233-271. [Internet] https://doi.org/10.1093/ehjci/jev014

https://academic.oup.com/ehjcimaging/article-lookup/doi/10.1093/ehjci/jev014

[26] Rudski, L.G., Lai, W.W., Afilalo, J., Hua, L., Handschumacher, M.D., Chandrasekaran, K., et al. (2010) Guidelines for the echocardiographic assessment of the right heart in adults: a report from the American Society of Echocardiography endorsed by the European Association of Echocardiography, a registered branch of the European Society of Cardiology, and the Canadian Society of Echocardiography. Journal of the American Society of Echocardiography, 23, 685-713.

https://doi.org/10.1016/j.echo.2010.05.010

http://www.ncbi.nlm.nih.gov/pubmed/20620859

[27] Bravo, M., Collado, L., Dardanelli, E., Araujo, B., Lipsich, J. and Moguillansky, S. (2012) Ultrasonography Measurement of Carotid Intima-Media Thickness in Pediatric Patients with Obesity, Familial Hyper-Cholesterolemia and Type 1 Diabetes. Pediatric, 76, 62.

[28] Hata, J., Ninomiya, T., Hirakawa, Y., Nagata, M., Mukai, N., Gotoh, S., et al. (2013) Secular Trends in Cardiovascular Disease and Its Risk Factors in Japanese. Circulation, 128, 1198-1205. https://doi.org/10.1161/CIRCULATIONAHA.113.002424

[29] Sakura, T., Morioka, T., Shioi, A., Kakutani, Y., Miki, Y., Yamazaki, Y., et al. (2017) Lipopolysaccharide-Binding Protein Is Associated with Arterial Stiffness in Patients with Type 2 Diabetes: A Cross-Sectional Study. Cardiovascular Diabetology, 16, Article No. 62. https://doi.org/10.1186/s12933-017-0545-3

[30] Asada, M., Oishi, E., Sakata, S., Hata, J., Yoshida, D., Honda, T., et al. (2019) Serum Lipopolysaccharide-Binding Protein Levels and the Incidence of Cardiovascular Disease in a General Japanese Population: The Hisayama Study. Journal of the American Heart Association, 8, e013628. https://doi.org/10.1161/JAHA.119.013628

[31] Schusterova, I., Jurko, A. and Minarik, M. (2013) Left Ventricular Systolic and Diastolic Function in Children with Overweight and Obesity. Bratislava Medical Journal, 114, 526-530. https://doi.org/10.4149/BLL_2013_110

[32] Balaji, S., DiLorenzo, M.P., Fish, F.A., Etheridge, S.P., Aziz, P.F., Russell, M.W., et al. (2019) Impact of Obesity on Left Ventricular Thickness in Children with Hypertrophic Cardiomyopathy. Pediatric Cardiology, 40, 1253-1257.

https://doi.org/10.1007/s00246-019-02145-9

[33] Hurtado-Sierra, D., Colin-Ramírez, E., Lena-Hernández, E.L., Sánchez-Cornelio, C., Trujeque-Ruiz, L., Aguilar-Morales, T.I., et al. (2019) Alteraciones cardíacas subclíni- 
cas detectadas por ecocardiografía en escolares Mexicanos con sobrepeso y obesidad. Archivos de Cardiología de México, 89, 222-231. https://doi.org/10.24875/ACM.M19000040

[34] Mangner, N., Scheuermann, K., Winzer, E., Wagner, I., Hoellriegel, R., Sandri, M. et al. (2014) Childhood Obesity: Impact on Cardiac Geometry and Function. JACC: Cardiovasc Imaging, 7, 1198-1205. https://doi.org/10.1016/j.jcmg.2014.08.006

[35] Alpert, M.A. (2001) Obesity Cardiomyopathy: Pathophysiology and Evolution of the Clinical Syndrome. American Journal of the Medical Sciences, 321, 225-236. https://doi.org/10.1097/00000441-200104000-00003

[36] Sokmen, A., Sokmen, G., Acar, G., Akcay, A., Koroglu, S., Koleoglu, M., et al. (2013) The Impact of Isolated Obesity on Right Ventricular Function in Young Adults. Arquivos Brasileiros de Cardiologia, 101, 160-168.

https://doi.org/10.5935/abc.20130142

[37] Yang, H., Huynh, Q.L., Venn, A.J., Dwyer, T. and Marwick, T.H. (2017) Associations of Childhood and Adult Obesity with Left Ventricular Structure and Function. International Journal of Obesity, 41, 560-568. https://doi.org/10.1038/ijo.2016.234

[38] Zeller, J., Strack, C., Fenk, S., Mohr, M., Loew, T., Schmitz, G., et al. (2016) Relation between Obesity, Metabolic Syndrome, Successful Long-Term Weight Reduction, and Right Ventricular Function. International Heart Journal, 57, 441-448.

https://doi.org/10.1536/ihj.15-403

[39] Baroncini, L.A.V., Sylvestre, L.de.C., Baroncini, C.V. and Filho, RP. (2017) Assessment of Carotid Intima-Media Thickness as an Early Marker of Vascular Damage in Hypertensive Children. Arquivos Brasileiros de Cardiologia, 108, 452-457.

https://doi.org/10.5935/abc.20170043

[40] Järvisalo, M.J., Jartti, L., Näntö-Salonen, K., Irjala, K., Rönnemaa, T., Hartiala, J.J., et al. (2001) Increased Aortic Intima-Media Thickness: A Marker of Preclinical Atherosclerosis in High-Risk Children. Circulation, 104, 2943-2947. https://doi.org/10.1161/hc4901.100522

[41] Meyer, A.A., Kundt, G., Steiner, M., Schuff-Werner, P. and Kienast, W. (2006) Impaired Flow-Mediated Vasodilation, Carotid Artery Intima-Media Thickening, and Elevated Endothelial plasma Markers in Obese Children: The Impact of Cardiovascular Risk Factors. Pediatrics, 117, 1560-1567.

https://doi.org/10.1542/peds.2005-2140

[42] Iannuzzi, A., Licenziati, M.R., Acampora, C., Salvatore, V., Auriemma, L., Romano, M.L., et al. (2004) Increased Carotid Intima-Media Thickness and Stiffness in Obese Children. Diabetes Care, 27, 2506-2508. [Internet]

https://doi.org/10.2337/diacare.27.10.2506

https://care.diabetesjournals.org/content/27/10/2506

[43] Al-Drawny, Z., Hamdy, S., Saleh, A., Abdel, A., El-Sammak, A. and Attia, H.M. (2020) Carotid Intima Media Thickness in Obese Egyptian Children and Adolescent. Egyptian Journal of Hospital Medicine, 80, 672-677. [Internet] https://dx.doi.org/10.21608/ejhm.2020.95264

http://egyptianjournal.xyz/801_19.pdf 